\title{
CRESCIMENTO DE MUDAS DE ALFACE EM SUBSTRATO ASSOCIADO A DOSES CRESCENTES DE Bacillus subtilis
}

Nathalia Calhabeu Ferreira ${ }^{1}$; Rita de Cássia Lima Mazzuchelli ${ }^{2}$; Eduardo Henrique Lima Mazzuchelli ${ }^{3}$; Fabio Fernando de Araujo ${ }^{4}$.

${ }^{1}$ Discente de agronomia da UNOESTE. ${ }^{2}$ Mestranda do Curso de Mestrado em Agronomia UNOESTE. ${ }^{3}$ Engenheiro Agrônomo. ${ }^{4}$ Docente da UNOESTE. E-mail: fabio@unoeste.br.

\section{RESUMO}

O objetivo foi avaliar o efeito das dosagens de Bacillus subtilis no substrato para a produção mudas de alface (Lactuca sativa). O experimento foi conduzido em estufa de produção de mudas, Unoeste, P. Prudente, SP. Foi utilizado o substrato comercial Bioplant ${ }^{\circledR}$, para o preenchimento de bandejas de poliestireno expandido. O substrato recebeu a aplicação da rizobactéria nas proporções de 0,$0 ; 0,5 ; 1,0 ; 2,0 ; 4,0 \%$. Foi utilizado o cultivar Vanda, com preenchimento de cinco bandejas. O delineamento experimental foi inteiramente casualisado, totalizando duzentas plantas por tratamento. As mudas foram mantidas por 26 dias em estufa. Foram retiradas vinte mudas por tratamento, para análises do comprimento da parte aérea e sistema radicular, massa fresca de parte aérea e sistema radicular. A utilização de Bacillus subtilis na proporção de $1 \%$ do substrato proporcionou melhor desenvolvimento dos parâmetros biométricos avaliados na produção de mudas de alface.

Palavras-chave: Lactuca sativa, rizobactéria, substrato, hortaliças, parâmetros biométricos.

\section{INTRODUÇÃO}

A alface (Lactuca sativa L.) da família Asteraceae (Compositae) originou-se de espécies silvestres, atualmente encontradas nas regiões de clima temperado, no sul da Europa e na Ásia Ocidental. É uma espécie herbácea com folhas finas e delicadas, que se organizam em rosetas ao redor de um caule diminuto e não ramificado (FILGUEIRA, 2008).

O aumento de hortaliças tem aumentado devido ao crescente aumento na população e, também pela tendência na mudança no hábito alimentar do consumidor, tornando-se necessário o aumento na produção. Então o consumidor torna-se cada vez mais exigente, havendo necessidade de produzir hortaliças em quantidade e qualidade, durante o ano todo (OHSE et al., 2001).

Para aumentar a produtividade e à sustentabilidade agrícola, é necessária a redução no uso de fertilizantes solúveis e no incremento de fontes não tradicionais de nutrientes, como adubação orgânica e a reciclagem de resíduos, como a utilização de cobertura morta (LIMA et al., 2009).

O sucesso de uma produção agrícola começa pela obtenção de mudas com boa qualidade, pois aquelas mal formadas darão origem a plantas com produção abaixo de seu potencial genético 
(TRANI et al., 2004). Para que ocorra o sucesso na produção de mudas o substrato deve fornecer condições para que a muda desenvolva suas raízes, portanto os substratos, quando bem formulados, permitem melhores condições ao desenvolvimento vegetal especialmente em cultivos protegidos, os quais exigem um ambiente radicular "refinado" (MENEZES JUNIOR et al., 2000).

Os produtores procuram adquirir mudas de melhor qualidade, com bom enraizamento e desenvolvimento de folhas, de maneira a permitir maior amplitude no período de transplante das bandejas para o campo. O tamanho das células dos recipientes e o tipo de substrato são os aspectos primordiais a serem estudados para a obtenção de mudas de qualidade, pois afetam diretamente o desenvolvimento e a arquitetura do sistema radicular bem como o fornecimento de nutrientes as mudas (TRANI et al., 2004).

As rizobactérias promotoras de crescimento de plantas (plant growth-promoting rhizobacteria - PGPR) proporcionam vários benefícios para as plantas, como o aumento nas taxas de germinação de sementes, no crescimento de raízes, grãos, folhas, área foliar, teor de nutrientes, maior tolerância à seca, atrasa a senescência foliar e, como destaque de sua utilização o biocontrole de doenças, através de ação direta contra o patógeno e ação indireta tornando a planta mais resistente (LUCY, REED, GLICK, 2004).

A bactéria Bacillus subtilis é habitante natural do solo, produz enzimas, e fitohormonios que proporcionam benefícios para as plantas, é descrita como promotora de crescimento de plantas, pode produzir os antibióticos bulbiformina, micosubtilina, bacilomicina, bacilizina, funginicina, também podem inibir fitopatógenos (ARAÚJO, 2008; SILVEIRA, 2001; ARAÚJO; HUNGRIA, 1999).

O objetivo do presente trabalho foi o de avaliar o efeito das dosagens de Bacillus subtilis incorporadas no substrato para a produção mudas de alface (Lactuca sativa L.).

\section{METODOLOGIA}

O experimento foi conduzido em estufa de produções de mudas, no Campus II da UNOESTE, na cidade de Presidente Prudente, oeste do estado de São Paulo, situada na coordenadas geográficas 51ㅇ 26'00" de longitude Oeste de Greenwich e 22ㅇ 07'30" de latitude Sul, com altitude de 433 metros. 
O clima da região é pela classificação de Köppen Aw como mesotérmico com verões quentes e período chuvoso bem definido nos meses de setembro a março e invernos secos com temperaturas mais amenas nos meses de abril a setembro.

Foi utilizado o substrato comercial Bioplant ${ }^{\circledR}$, para o preenchimento de bandejas de poliestireno expandido com 200 células.

Foram separadas porções de $1,0 \mathrm{~kg}$ do substrato comercial Bioplant ${ }^{\circledR}$, os quais receberam a aplicação de Bacillus subtilis, nas dosagens de 0,$0 ; 0,5 ; 1,0 ; 2,0 ; 4,0 \%$, correspondentes a 0,0; 5,0; 10,0; 20,0 e 40,0 gramas.

O plantio foi realizado no dia 14 de junho de 2013, foram semeadas uma semente de alface cultivar Vanda, em cada uma das células, ao todo foram preenchidas cinco bandejas. 0 delineamento experimental foi inteiramente casualisado com vinte repetições.

As mudas foram mantidas por 26 dias em estufa, recebendo irrigação periódica. Após este período foram retiradas vinte mudas aleatoriamente de cada uma das bandejas para as análises de comprimento parte aérea, comprimento do sistema radicular, massa fresca de parte aérea e massa fresca do sistema radicular.

Para a análise da massa fresca, as mudas foram retiradas da bandeja, fracionadas em parte aérea e sistema radicular, lavadas para a remoção do substrato, encaminhadas a balança de precisão para determinação da massa fresca de parte aérea e sistema radicular.

Os dados obtidos foram submetidos à análise de variância e de regressão. Para avaliar as doses de Bacillus subtilis foi aplicada a regressão polinomial e ajuste das equações.

\section{RESULTADOS}

O comprimento da parte aérea das mudas de alface apresentou comportamento quadrático em resposta às dosagens de Bacillus subtilis aplicadas ao substrato, a dosagem de 1,0\% possibilitou uma melhor resposta. A maior dosagem, de 4,0\% apresentou menor desenvolvimento das mudas (Figura 01). 


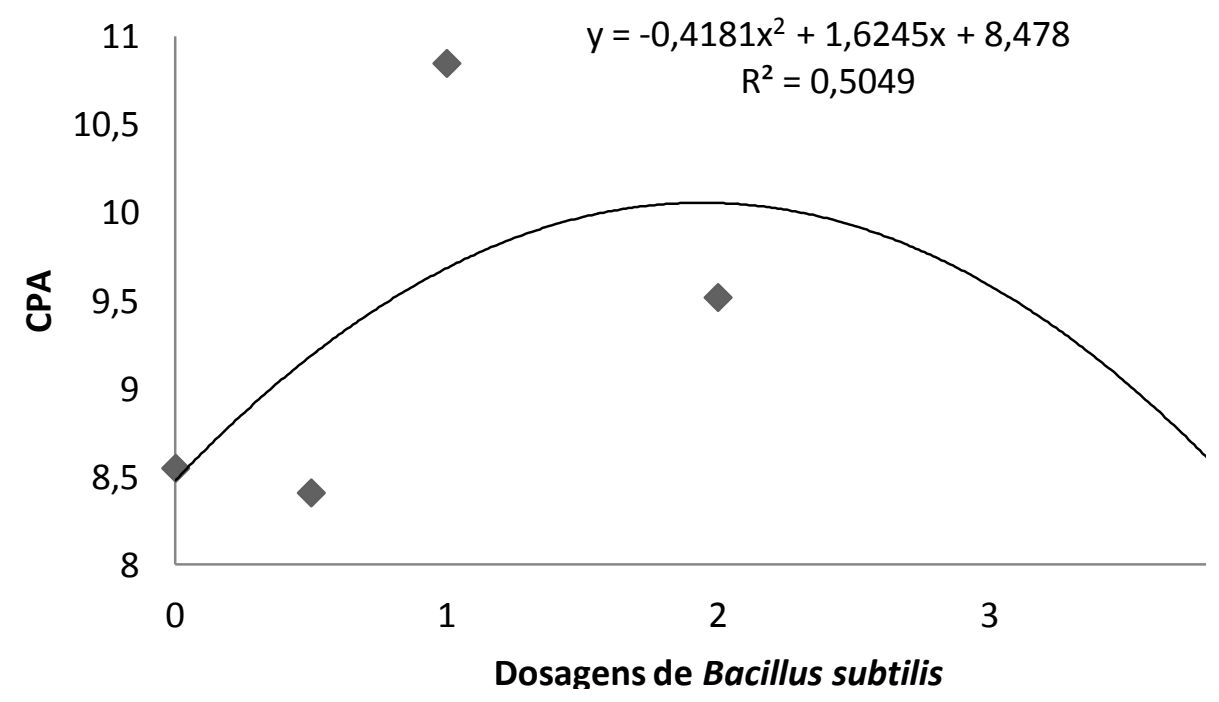

Figura 01. Comprimento da parte aérea (CPA $-\mathrm{cm}$ planta $^{-1}$ ) das mudas de alface submetidas a dosagens crescentes de Bacillus subtilis.

O comprimento do sistema radicular mostrou melhor desenvolvimento com as dosagens de 0,5 e $1,0 \%$ de $B$. subtilis, a dosagem de $4 \%$ apresentou o menor crescimento radicular (Figura 02).

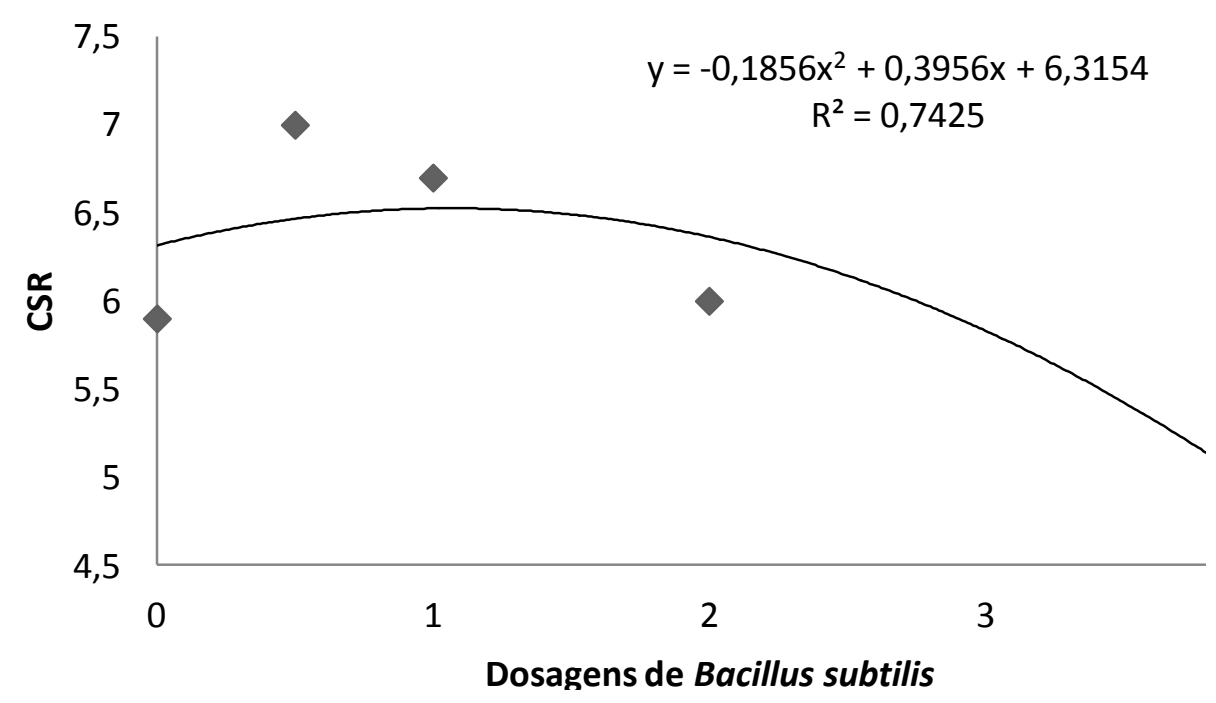

Figura 02. Comprimento do sistema radicular (CSR - cm planta ${ }^{-1}$ ) das mudas de alface submetidas a dosagens crescentes de Bacillus subtilis.

A dosagem de 1,0\% apresentou um maior resposta a massa fresca da parte aérea das mudas de alface submetidas às dosagens de Bacillus subtilis em relação as demais dosagens avaliadas (Figura 03). 


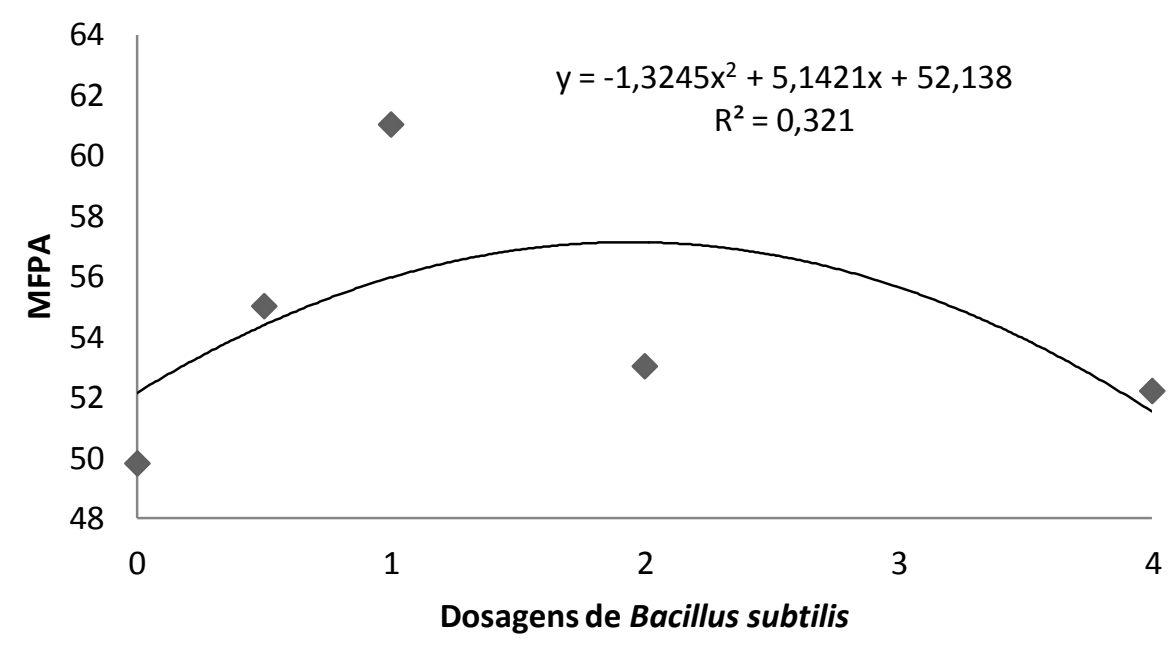

Figura 03. Massa fresca da parte aérea (MFPA - g planta ${ }^{-1}$ ) das mudas de alface submetidas a dosagens crescentes de Bacillus subtilis.

A massa fresca do sistema radicular apresentou o maior desenvolvimento na dosagem de $1,0 \%$ de $B$. subtilis, a dosagem de $0 \%$ apresentou a menores médias da massa do sistema radicular (Figura 04).

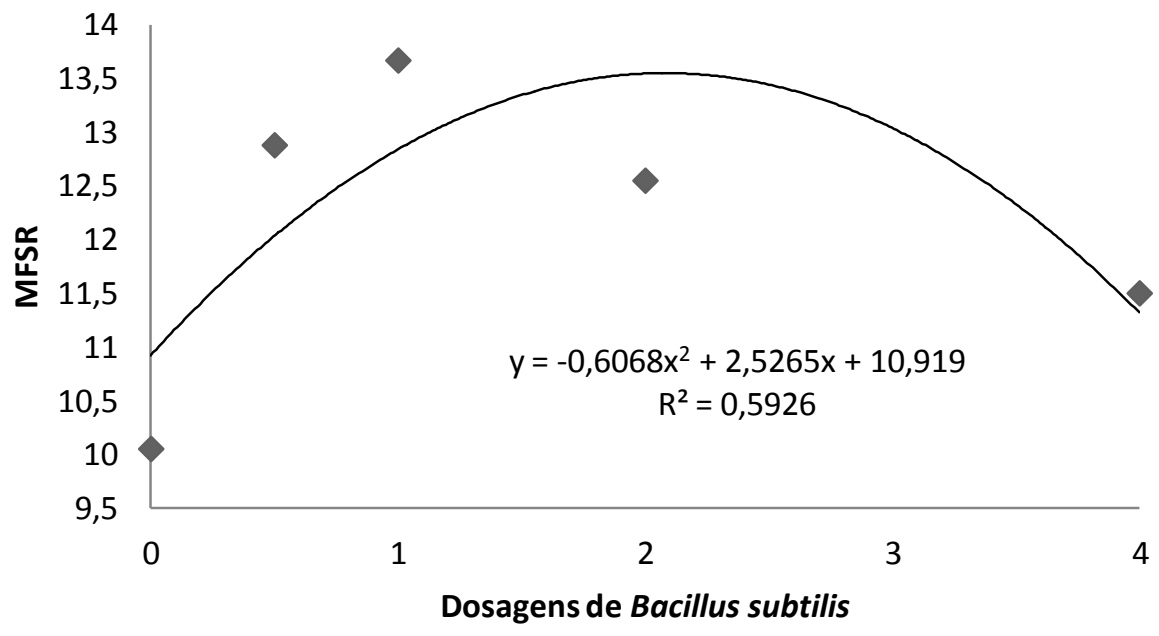

Figura 04. Massa fresca do sistema radicular (MFSR - g planta ${ }^{-1}$ ) das mudas de alface submetidas a dosagens crescentes de Bacillus subtilis. 


\section{DISCUSSÃO}

A utilização do Bacillus subtilis na formação de mudas de alface contribui positivamente até a dosagem de 1,0\%, após esta dosagem começa haver um declínio das variáveis analisadas.

A bactéria Bacillus subtilis tem a capacidade de colonizar as raízes através da formação de uma camada fina sobre elas. A colonização do sistema radicular possibilita uma situação de competição com outras espécies de microrganismos (KILIAN et al., 2000).Confirmando com Lucy, Reed e Glick (2004) que afirmam que as rizobactérias promotoras de crescimento de plantas proporcionam vários benefícios para as plantas, como o aumento nas taxas de germinação de sementes, crescimento de raízes, área foliar, aumentando o teor de nutrientes.

As hortaliças são cultivadas em curto período, consequentemente as medidas que possibilitem uma melhor qualidade do produto final, sem onerar muito os custos são importantes para o produtor (NUNES et al., 2007).

As técnicas que possibilitam melhorar as condições das mudas, como por a adição de adubações, constituem-se em um fator indispensável para o desenvolvimento das mudas, aumentando acelerando consideravelmente o crescimento das mesmas, diminuindo os custos de produção das hortaliças (MENDONÇA et al., 2007)

As mudas são confeccionadas na maioria das vezes com substratos comerciais, prontos para a utilização, entretanto, estes nem sempre atendem as exigências das mudas, portanto, melhorar as condições do substrato é uma medida necessária para aumentar a qualidade das mudas de hortaliças produzidas (TRANI et al., 2007).

\section{CONCLUSÃO}

A utilização de Bacillus subtilis na proporção de $1 \%$ do substrato proporcionou melhor desenvolvimento dos parâmetros biométricos avaliados na produção de mudas de alface.

\section{REFERÊNCIAS}

ARAÚJO, F. F. Inoculação de sementes com Bacillus subtilis, formulado com farinha de ostra e desenvolvimento de milho, soja e algodão. Ciência e agrotecnologia, Lavras, v.2, p. 456-462, 2008.

ARAÚJO, F. F.; HUNGRIA, M. A. Nodulação e rendimento de soja co-infectada com Bacillus subtilis e Bradyrhizobium japonicum / Bradyrhizobium elkanii. Pesquisa Agropecuária Brasileira, Brasília, v.34, n.9, p.1633-1643. 1999. http://dx.doi.org/10.1590/S0100-204X1999000900014

COELHO, L.F.; FREITAS, S.S.; MELO, A.M.T.; AMBROSANO, G.M.B. Interação de bactérias fluorescentes do gênero Pseudomonas e de Bacillus spp. com a rizosfra de diferentes plantas.

Revista Brasileira de Ciência do Solo, Viçosa, v.31, p. 1413-1420, 2007. 
Encontro de Ensino, Pesquisa e Extensão, Presidente Prudente, 21 a 24 de outubro, 2013

FILGUEIRA, F.A.R. Novo Manual de Olericultura: agrotecnologia moderna na produção e comercialização de hortaliças. Viçosa, Editora da UFV, 402p. 2008.

LIMA, M.E.; CARVALHO, D.F.; SOUZA, A.P.; GUERRA, J.G.M.; RIBEIRO, R.L.D. Desempenho da alface em cultivo orgânico com e sem cobertura morta e diferentes lâminas d'água. Ciência e agrotecnologia. [online]. vol.33, n.6, pp. 1503-1510. 2009.

KILIAN, M.; STEINER, U.; KREBS, B.; JUNGE, H.; SCHMIEDEKNECHT, G.; HAIN, R. FZB24 ${ }^{\circledR}$ Bacillus subtilis-mode of action of a microbial agent enhancing plant vitality. Pflanzenschutz-Nachrichten Bayer, v. 1, n. 0, p. 72-93, 2000.

LUCY, M.; REED, E.; GLICK, B. R. Applications of free living plant growth-promoting rhizobacteria. Antonie van Leeuwenhoek, v. 86, n. 1, p. 1-25, 2004.

http://dx.doi.org/10.1023/B:ANTO.0000024903.10757.6e

PMid:15103234

MENDONÇA, V.; TOSTA, M.S.; MACHADO, J.R.; GOULART JÚNIOR, A.R.; TOSTA, J.; BISCARO, G.A. Fertilizante de liberação lenta na formação de mudas de maracujazeiro amarelo. Ciênc. agrotec., Lavras, v. 31, n. 2, p. 344-348, mar./abr., 2007.

MENEZES JÚNIOR, F.O.G.; FERNANDES, H.S.; MAUCH, C.R.; SILVA, J.B. Caracterização de diferentes substratos e seu desempenho na produção de mudas de alface em ambiente protegido.

Horticultura Brasileira, Brasília, v. 18, n. 3, p. 164-170, novembro 2000.

http://dx.doi.org/10.1590/S0102-05362000000300004

NUNES, M.U.C.; SANTOS, J.R.; SOUZA, R.A. Sistema de produção orgânico de repolho em consorcio com o coentro em Sergipe. Circular técnica 49. Sergipe. AL. 2007.

OHSE, S.; DOURADO-NETO, D.; MANFRON, P.A.; SANTOS, O.S. Qualidade de cultivares de alface produzidos em hidroponia. Scientia Agricola, v.58, n.1, p.181-185, jan./mar. 2001.

http://dx.doi.org/10.1590/S0103-90162001000100027

SILVEIRA, E. B. Bactérias promotoras de crescimento de plantas e biocontrole de doenças. In: MICHEREFF, S.J.; BARROS, R. Proteção de plantas na agricultura sustentável. Recife: UFRPE, Imprensa Universitária. p. 70- 100. 2001.

TRANI, P.E.; FELTRIN, D.M.; POTT, C.A.; SCHWINGEL, M. Avaliação de substratos para produção de mudas de alface. Horticultura Brasileira, v. 25, p. 256-260. 2007.

http://dx.doi.org/10.1590/S0102-05362007000200025

TRANI, P.E.; NOVO, M.C.S.S.; CAVALLARO JÚNIOR, M.L.; TELLES, L.M.G. Produção de mudas de alface em bandejas e substratos comerciais. Horticultura Brasileira, Brasília, v.22, n.2, p.290-294, abril-junho 2004. http://dx.doi.org/10.1590/S0102-05362004000200025 